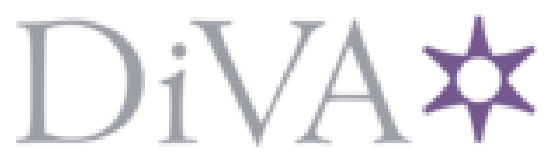

http://www.diva-portal.org

\title{
Postprint
}

This is the accepted version of a paper published in Work: A journal of Prevention, Assessment and rehabilitation. This paper has been peer-reviewed but does not include the final publisher proof-corrections or journal pagination.

Citation for the original published paper (version of record):

Coelho, D A., Lourenço, M L. (2021)

Dynamics of forearm muscle activity in slanted computer mice use

Work: A journal of Prevention, Assessment and rehabilitation, 68(1): 123-135

https://doi.org/10.3233/WOR-203242

Access to the published version may require subscription.

N.B. When citing this work, cite the original published paper.

Permanent link to this version:

http://urn.kb.se/resolve?urn=urn:nbn:se:hj:diva-50599 


\section{Dynamics of Forearm Muscle Activity in Slanted Computer Mice Use}

Denis A. Coelho ${ }^{1 *}$, Miguel L. Lourenço ${ }^{2,3}$

1 - Dept. of Supply Chain and Operations Management; School of Engineering; Jönköping University, 55111Jönköping, Sweden; 2 - C-MAST: Centre for Mechanical and Aerospace Science and Technologies, Universidade da Beira Interior, 6201-001 Covilhã, Portugal; 3 Engineering and Technology Technical Scientific Unit \& Research Unit for Inland Development, Technology and Management School, Guarda Polytechnic Institute, 6300-559 Guarda, Portugal

* corresponding author- Telephone: +4636101351, email: denis.coelho@ju.se, ORCID ID: 0000-0001-9759-9133;

Telephone: +351960077410, email: mlopes@ipg.pt, ORCID ID: 0000-0002-5028-1205 


\title{
Dynamics of Forearm Muscle Activity in Slanted Computer Mice Use
}

\begin{abstract}
BACKGROUND: Static muscular activity of muscles activated in the use of the conventional PC mouse is believed to represent a higher risk for the musculoskeletal health of the user than dynamic muscular activity. OBJECTIVE: This paper presents a compounded muscular activity dynamics indicator (akin to percent relative range), enabling comparison between computer handheld pointing devices. METHODS: This muscular dynamism approach considers baseline muscular activity (APL, ECR, ECU and ED) relative to the Maximum Voluntary Contraction as well as the dynamics of muscular activation. The latter is computed as the ratio of the difference between APDF90 and APDF10 divided by APDF50 (APDF-Amplitude Probability Distribution Function for the 90th, 50th and 10th percentiles). The paper demonstrates the approach with results of comparative evaluation of a horizontal, a slanted and a vertical PC mouse, through surface EMG monitoring of 20 participants performing standardized graphical task with the devices. RESULTS: Hand size impacts muscular activity dynamics in these 4 muscles, which supersedes differences in device geometry, across the range of devices tested. CONCLUSION: Smaller devices relative to hand size foster more dynamic muscular activity.
\end{abstract}

Keywords: Graphical tasks, Static contractions, Hand size; Conventional mouse; Percent relative range; APL; ECR; ECU; ED; APDF; MVC; S-EMG; Dynamic muscular activity.

Funding details: This work was funded in part by Fundação para a Ciência e a Tecnologia project UID/EMS/00151/2013 C-MAST.

\section{Introduction}

Prevalence of static muscular activity of muscles activated in the use of the conventional PC mouse is believed to represent a higher risk for the musculoskeletal health of the user than dynamic muscular activity. Static (or isometric) muscular activities concern physical effort caused by a posture that is maintained over a long period of time. This type of effort promotes the increase in the load of the contracted muscles, which contributes to rapidly achieving muscular fatigue [1]. The absence of dynamic activation of a contracted 
muscle hinders the blood flow that is needed to transport nutrients to the muscle and to remove residual muscular metabolic products [1]. This notwithstanding, higher levels of activation are potentially more harmful than lower values of activation, due to more fatigue being caused.

Dynamic (or isotonic) muscular activation is where there is contraction and relaxation resulting in movement [2]. Dynamic muscular work is less tiring and more efficient than static work [3]. During dynamic work a muscle contracts and relaxes rhythmically which makes it act like a pump for the flow of blood in the blood vessels, allowing the blood to supply more oxygen and take away more lactic acid than during static work [4].

According to Søgaard et al. [5], activities that imply repeated movements are typically accepted as implying dynamic muscular efforts without taking into account the eventual occurrence of repeated muscular static efforts. Risks related to static efforts probably arise from the fact that muscular contraction is continuously maintained. There is a set of activities where static 'low level' and long duration contractions occur. Among these activities, Sjøgaard and Jensen [6] name computer work, especially work with computer aided designing (CAD). Therefore, these authors define 'low level' static effort as a condition associated to muscular work in which the muscle is activated at such a low order level that it allows work to be maintained over a long period of time. Use of computer handheld pointing devices that causes pronation of the forearm, such as the conventional PC mouse, may foster occurrence of this type of static muscular activity, which may eventually indicate potential risk factors related to musculoskeletal disorders. The computer mouse's shape (its geometry) can be assessed through the use of surface electromyography (SEMG) by measuring the activity levels of certain muscles during the use of the device [7]. Wrist extension is associated to musculoskeletal disorders of the hand, namely through compression of the median nerve that crosses the carpal tunnel. Moreover, ulnar deviation is associated with injury of the ulnar nerve [7]. It is also known that the patterns of muscle activation of the finger extensor muscles (needed to lift and maintain the fingers above the PC mouse buttons) combined with wrist extension postures may contribute to occurrence of pain and discomfort in the upper extremities during intensive use of the computer mouse [8-15]. Thus, considering the aim of this study which consists in characterizing the dynamics of forearm muscle activity in computer handheld pointing device use monitored with surface EMG during the performance of standard 
graphic tasks [16], the monitoring of the activity of four muscles of the forearm of 20 participants has been performed [17]. The muscles that had their activity monitored were judiciously selected.

Factors, identified by Ullman et al. [18] as contributing to repetitive strain injuries and discomfort in the upper extremity used for controlling the mouse, were: static tension in muscles, not designed to be statically tensed, such as the trapezius, levator scapulae, as well as the hand and finger extensors [12]; wrist extension [19-22]; ulnar deviation [20, 23]; pronation of the hand [12]; abduction of the forearm (outward rotation of the humerus) [24,25]; repetitive motions [19, 20, 25, 27]; fixed working postures [28]; long work sessions [29]; as well as mental stress [30].

Ullman et al. [18] hypothesized that the large differences in muscular activity found between pointing devices could not be explained by differences in force needed to perform the actual mechanical movement of the mice. These authors assumed that the extra activity was an increase in static rather than dynamic, muscular activity. In the current study, we propose to compare the level of static-dynamic activity across the pointing devices, based on the time changes of the intensity of the contractions.

\section{Materials and Method}

\subsection{Muscle Selection}

Wrist extension activity can be monitored through electromyographic activity of the Extensor Digitorum Communis (EDC or just ED), Extensor Carpi Ulnaris (ECU) and Extensor Carpi Radialis (ECR) muscles, whereas the extension of the medial fingers occurs through EDC muscular activity, with slight or no activity of the other two said muscles [31]. Furthermore, registered electromyographic activity of the ECR and ECU muscles enables monitoring radial and ulnar deviations of the wrist [31]. Several studies include the monitoring of the electromyographic activity of the EDC, ECU and ECR forearm muscles [8, 11, 28, 31$]$. Inadequate and potentially harmful postures that are likely to be adopted during the use of the computer mouse involve wrist extension and, or, extension of the medial fingers, as well as radial deviation and ulnar deviation of the wrist or hand [14]. Additionally, the selection process of the muscles whose activity was 
monitored also received the useful and personal counselling given by Professor David M. Rempel [33]. After weighing all the information from literature and expert advice, the monitoring of the ECR, ECU, ED and the Abductor Pollicis Longus (APL) muscles was performed.

\subsection{Electrode Placement}

The surface electrodes used to collect the electromyographic signals from ECR, ECU and ED muscles were placed following Perotto's [34] guidelines. Even though the guidelines refer to insertional electromyography [34], the areas indicated do not present any other muscle in an outer layer. During the surface electrodes placement process the $\mathrm{x}$ area was always being touched and checked while the participant activated the chosen muscle, according to Table 1 (see also Figure 1). For the APL muscle, the best spot to apply the sensor was chosen according to Criswell's [31] guidelines considering the monitoring of the APL muscle activity using S-EMG.

Table 1 about here

Figure 1 about here

\subsection{Computer mice assessed}

The devices subjected to usability evaluation testing are shown in Fig. 2 with their technical specifications. The Anker model (slanted 60 degress) and Evoluent model (slanted 90 degrees) are available in the market and both are presented by their respective manufacturers as bearing the 'ergonomic' seal. The former is assumed to be a forearm pronation reducer, designed to increase functionality and comfort, designed to support the thumb and facilitate grip by fitting the contour of the palm. The second device cancels forearm pronation, supporting the hand and preventing twisting of the forearm during use. The rightmost pointing 
device shown in Figure 1 is the reference conventional model, the Microsoft optical 200 device. All devices except for Evoluent were used in the 1000 dpi resolution tests. The Evoluent model comes with several levels of resolution but does not have the value $1000 \mathrm{dpi}$, and was used at $1300 \mathrm{dpi}$. All devices are wired. Figure 2 shows the exterior dimensions of each device, the mass, the characteristic angle of inclination of the surface that supports the palm (relative to the horizontal working plane), and its designation.

Figure 2 about here

\section{$2.4 \quad$ Test tasks}

The tasks of pointing and selecting graphic entities, used and presented in the work developed by Odell and Johnson $[35,36]$, satisfy the requirements resulting from the operations of this type carried out in the course of the CAD activity. In that study, 12 participants tested the various computer mice during the performance of pointing tasks. These tasks present three levels of difficulty through the dimensions of the circular targets, which are larger in the task of pointing large and decrease in size in the other two tasks (medium and small). In each task, one of the 18 circular targets is activated randomly and only 'turns off' when selected by the mouse cursor, after which the diametrically opposite circle (at $180^{\circ}$ ) is activated, which in turn only turns off when selected, then another random circle is activated. According to the same authors, the dimensions of the targets in the pointing large task are similar to those of the folders and icons on a desktop computer, and the size of the targets in the pointing small task is similar to the size of the smaller characters.

In the work developed by Houwink et al. [32], 30 participants tested two computer mice while performing pointing, dragging and steering tasks. Each omnidirectional task took about a minute to complete. In these tasks the distribution of targets in space took on a geometry similar to the one used by Odell and Johnson [35], in spite of assuming much larger distances between diametrically opposing centers. In the dragging task, subjects had to select the active target (by clicking the mouse button) and drag it to the diametrically opposite circle by releasing the mouse button on the target. In the steering task, subjects had to 
move, as rectilinearly as possible, the active target from one point to another within the boundaries of a twodimensional 'tunnel'.

In this regard, regarding tasks to be performed in comparative tests between computer mice, there seems to be no consensus. When Lee et al. [8] tested alternative ways to click the left mouse button (adapted model), they used pointing, dragging and steering tasks. These authors considered 15 circular targets of 7.5 $\mathrm{mm}$ diameter for the pointing task, a sequence of 20 horizontal tunnels arranged horizontally and vertically with different lengths and, or, widths for the steering task and selecting and dragging shapes by fitting them into their 'shadows' in the dragging task.

In computer-aided design and design (CAD), where the keyboard is almost not used, besides the intensive use of this manual tool of interface with the computer, the work is characterized by pointing and clicking (pointing) graphic entities (targets) of medium and small dimensions, dragging using the three mouse buttons alternately, and steering. In this context, scroll is still used, typically with the zoom function. Thus, to test the devices of interest (Figure 2) we chose to structure the test tasks in the following way: pointing large, medium and small tasks configured identically to Odell and Johnson [34] and dragging and steering modes configured appropriately from the configuration reported by Houwink et al. [32]. The dragging test tasks sequentially use the left button, the middle button and the right mouse button and always with the referred sequence. Figure 3 illustrates all the tasks. In the tasks of pointing, the test is initiated by the participant when she or he clicks on the center circle and the action takes place as in Odell and Johnson [35], only with the difference of the sequence increasing the degree of difficulty, starting in the pointing large task and ending in the pointing small task. The devices were used by participants in a completely random manner. The steering task had targets of $7 \mathrm{~mm}$ in diameter, like the dragging task, because it was considered that the interest would be to maintain the rectilinear trajectory of the displacement, knowing also that the task of pointing small had very small targets (diameter of $2 \mathrm{~mm}$ ). The scroll task was only used for subjective evaluation of usability, and to record the muscle activity of the main muscles involved, and it was not possible to determine the efficiency or effectiveness of using the middle button in the scroll function. 


\subsection{Participants}

The study took place during July 2015 and had 20 healthy young adult participants (10 male subjects and 10 female subjects). The sessions took place according to the availability of each participant. Participants were recruited from finalist students and professional graduates of Equipment Design (14 in number). Young students of engineering and architecture, and graduates in these areas, as well as professionals in these areas (six in number) participated. All 20 participants were considered CAD practitioners because they had two or more years of $\mathrm{CAD}$ training and practice. All subjects were right-handed and had normal or corrected vision to normal. Table 2 shows sample data, such as sex, age, length and width of the right hand. The length and width of the right hand were measured according to Pheasant and Haslegrave. [37] Table 3 shows the data for the pooled sample, indicates the size of the hand from the sum of its length to its width (mean and standard deviation) and also shows the number of participants whose hand size is less than or greater than the mean value of the sample.

Table 2 about here

Table 3 about here

\subsection{Indicator of muscular activity dynamism (Dind - Dynamics indicator)}

The EMG data normalized based on their MVC values (maximum voluntary contraction) [31, 38-42] for each of the 4 muscles and for each individual were subsequently transformed in order to obtain the 
Amplitude Probability Distribution Function, hereinafter referred to as APDF. APDF values were obtained according to Hagberg [43] and Jonsson [44] for the $10^{\text {th }}, 50^{\text {th }}$ and $90^{\text {th }}$ percentiles.

Concerning static 'low-level' efforts, Sjøgaard and Jensen [6] report that static stresses measured by electromyography and analyzed through the amplitude probability distribution (APDF) function of the electromyographic signal, where the static level is typically defined as the probability $\mathrm{P}=0.1$ does not guarantee the monitoring of variations in muscle length, which means that dynamic muscle contractions can occur during the same time window. As a consequence, and within the scope of the research developed in this study, it is considered of all interest to develop a new indicator of dynamic activity, as opposed to the static level that has been and continues to be associated with APDF10. A new indicator of dynamic muscle activity was defined, defined as Dind= [(APDF90-APDF10)/APDF50]. The dynamic index (Dind) is a dimensionless ratio between the range of muscle activation (APDF90 - APDF 10) and the mid-level of intensity of contraction (APDF50). Dind is similar to percent relative range. A greater range with a smaller mid-level will yield a higher value of the dynamic index indicating more dynamic muscle contraction over time. Conversely, a smaller range of muscle activation or a greater mid-level will indicate more static contractions over time. Hence, this dynamics indicator enables comparisons across alternative use cases in general, and pointing devices, in this particular study. The Dind indicator was calculated for all devices, muscle and subject combinations of the sample. This new indicator, if used by grouping the set of muscles of interest, may help to understand the static and dynamic global muscular 'involvement' related to the different tasks of the test. It can also be used to determine the level of 'dynamism' of muscle activity associated with a given device for a specific task.

Fractional use time of the several operations that were tested, representative of Computer Aided Design operations taken from an observational study [45], enabled a compounded overview of the dynamics of muscular activity across the range of tested devices, according to equation 1 (Dindcomp - dynamic time compound index created). Hence, fractional time of use in CAD software use (AutoDesk Inventor) per operation as reported by Coelho and Lourenço [45], was used to create a compounded dynamics index, per subject and per muscle monitored, according to equation 1, with completing information in Table 4 . The compounded dynamic index (Dind_compounded) integrates the dynamic load profiles that a muscle 
undergoes according to the device being used over the course of performing different tasks, of which the fractional time for each task is known or estimated.

Dind_compounded $=\sum$ (Activity time fraction $) *$ Dind_activity

Table 4 about here

\section{Results and analysis}

IBM SPSS v.26 was used for statistical analysis of the data. Previous research identified the size of the hand as a decisive factor in muscular activity (smaller hands involve higher relative values of muscular activity (in MVC percentage) than bigger hands for the same device) $[16,46]$. A time weighted compounded and muscle by muscle overview of the results of APDF90, APDF10, APDF50 and the dynamic index is shown in Figures 4, 5, 6 and 7, by hand size and by device slant angle.

\section{Figure 4 about here}

A two-way mixed RM-ANOVA was conducted to investigate the impact of device angle and hand size on dynamics of APL muscle activation (Fig. 4). There was not a significant main effect on hand size, F(1, $18)=2.24, \mathrm{p}=0.128$. Moreover, there was no significant main effect of device angle, $\mathrm{F}(2,36)=0.32, \mathrm{p}=0.698$. There was no significant interaction between device angle and hand size, $F(2,36)=0.14, p=0.815$. Pairwise comparisons with Bonferroni adjustment for multiple comparisons did not reveal significant differences between the different degrees angled devices. 
A two-way mixed RM-ANOVA was conducted to investigate the impact of device angle and hand size on dynamics of ECR muscle activation (Fig. 5). There was not a significant main effect on hand size, F(1, $18)=3.53, p=0.077$. Moreover, there was no significant main effect of device angle, $F(2,36)=0.23, p=0.797$. There was no significant interaction between device angle and hand size, $F(2,36)=1.34, p=0.275$. Pairwise comparisons with Bonferroni adjustment for multiple comparisons did not reveal significant differences between the different degrees angled devices.

\section{Figure 6 about here}

A two-way mixed RM-ANOVA was conducted to investigate the impact of device angle and hand size on dynamics of ECU muscle activation (Fig. 6). There was a significant main effect on hand size, F(1, $17)=4.86, p=0.041$, with participants with greater hand size achieving greater dynamics in ECU muscle

activation than participants with hand size below the mean. Moreover, there was a significant main effect of device angle, $F(2,34)=3.79, p=0.033$. There was no significant interaction between device angle and hand size, $\mathrm{F}(2,34)=3.006, \mathrm{p}=0.063$. Pairwise comparisons with Bonferroni adjustment for multiple comparisons revealed significant difference $(p=0.018)$ between the 60 and 90 degrees angled devices.

\section{Figure 7 about here}

A two-way mixed RM-ANOVA was conducted to investigate the impact of device angle and hand size on dynamics of ED muscle activation (Fig. 7). There was not a significant main effect on hand size, F(1, $18)=2.61, p=0.124$. Moreover, there was no significant main effect of device angle, $F(2,36)=1.98, p=0.153$. There was no significant interaction between device angle and hand size, $\mathrm{F}(2,36)=0.06, \mathrm{p}=0.938$. Pairwise comparisons with Bonferroni adjustment for multiple comparisons did not reveal significant differences between the different degrees angled devices. 


\section{Discussion}

In this research, a compounded indicator of muscle activity dynamism is proposed, based on a relation between the values of the Amplitude Probability Distribution Function relative to muscle contraction, to distinguish tasks and, or, computer pointing manual devices pointing to, relevant to researchers and ordinary users of CAD. The combined analysis of APDF baseline values (APDF10) and the muscular dynamism indicator (Dind) allows to take into account both the magnitude of muscular activation and its more static or dynamic nature. According to the definition of static low level effort advocated by Sjøgaard and Jensen [6], application cases are presented in the present paper. The cases of qualitative evaluation regarding the static dynamic muscular activity (mean APDF90 of the order of 10 to $20 \%$ of MVC for APL, ECR, ECU and ED) showed statistically significant results for most muscles across categories of hand size, task by task, and also in an overall compounded index, crated according to the fractional use time [45]. These differences supersede differences across devices, which hardly attain any statistical significance. The comparative value that Dind can bring is rooted in its nature of a single number indicator that can summarize the dynamics of muscle contraction enabling comparisons among similar devices, with only minor differences among themselves, such as the slant angle.

The results indicate that hand size is a crucial factor in determining the nature of the muscular activity dynamics in the forearm, with statistically significant differences found for one of the forearm muscles. This supersedes differences in device geometry, across the range of devices tested. Muscle ECU, is where the most striking differences in the dynamic compounded index across hand size are statistically proven for every slanted device. This muscle is involved in ulnar deviation of the hand at the wrist. Overall, more static muscular activation was registered for the smaller hand size than for the larger hand size (statistically significant differences). 


\subsection{Study limitations}

This study is based on an empirical controlled S-EMG study involving 20 participants, selected as a convenience sample, due to practical limitations. The dynamic compounded index is based on a particular software (Autodesk Inventor) and is hence only specific to a particular activity. Moreover, the set of pointing devices compared is quite limited, but with varying archetypes and sizes. Another limitation springs from the limited set of muscles that were monitored with S-EMG. Although these were selected with support from previous literature, as well as expert consultation, other muscles might have yielded differing results, regarding the role of hand size on the dynamics of muscular activity. This notwithstanding, the exemplification enabled by this example allowed the characterization of the dynamics of muscular activity in the use of PC mice for CAD tasks in one single indicator per muscle, enabling comparison.

A further limitation of this study is that it is likely underpowered statistically. Several of this study's findings are close to the statistical significance threshold. Given these strong trends, it seems likely that significance would have been reached with additional participants.

\subsection{Future research}

An empirical approach to assessing PC mice use, besides usability (a short-term outlook) [45, 47], concerns risks for musculoskeletal health, which are assessed from posture and muscular activity. Increasing dynamics of muscular activity, diminishing musculoskeletal health risks in the long run, springs from use of smaller devices in relation to hand anthropometry, as the current study indicates.

Future research springing from this study is envisaged in several directions. On the one hand, testing the application of the dynamics index in a wider range of computer handheld pointing devices, to ascertain whether similar devices with different sizes yield consistent results with this study's findings. It is expected that the smaller device yields higher dynamics than the bigger device for each participant (irrespective of hand size). Another direction for future studies is the application of the dynamics index to a wider set of muscles, as well as in other domains of application, beyond the realm of computer handheld pointing devices. 


\section{Conclusion}

A compounded indicator for the dynamics of muscular activity has been proposed, based on the Amplitude Probability Distribution Function of the Electromyography Signal in percentage of Maximum Voluntary Contraction. A single value can thus be calculated that represents the dynamics of muscular activity per muscle monitored using surface electromyography. This indicator (Dind - Dynamics indicator) enables comparison between alternative artifacts used to support an activity. The paper exemplified the case of computer handheld pointing devices in the activity of computer aided design, in particular, using AutoDesk Inventor, based on a previous study by the authors [45]. In this domain of application, hand size is a crucial factor in determining the nature of the muscular activity dynamics in the forearm muscles monitored, which supersedes differences in device geometry, across the range of devices tested (a standard, a slanted and a vertical pointing device). Muscular dynamics differences across devices was very similar overall, but differences were found in muscular dynamics between hand sizes. The results show that smaller computer handheld pointing devices relative to hand size foster more dynamic muscular activity.

\section{Acknowledgement}

This work was supported by Portuguese funds through Portuguese Foundation for Science and Technology (FCT) through the Research Centre for Mechanical and Aerospace Science and Technologies, under (UID/EMS/00151/2013/C-MAST). The authors thank the thoughtful and constructive critique that the manuscript received from anonymous peer-reviewers, contributing to greatly enhance this article.

\section{References}

1. Enoka RM, Duchateau J. Muscle fatigue: what, why and how it influences muscle function. The Journal of physiology. 2008 Jan 1;586(1):11-23.

2. Josephson RK. Contraction dynamics and power output of skeletal muscle. Annual review of physiology. 1993 Mar;55(1):527-46. 
3. Westgaard RH, Vasseljen O, Holte KA. Trapezius muscle activity as a risk indicator for shoulder and neck pain in female service workers with low biomechanical exposure. Ergonomics. 2001 Feb $1 ; 44(3): 339-53$.

4. Anghel M, Argeanu V, Talpo C, Lungeanu D. Musculoskeletal disorders (MSDS) consequences of prolonged static postures. J Exper Med Surg Res. 2007;4:167-72.

5. Søgaard K, Sjøgaard G, Finsen L, Olsen HB, Christensen H. Motor unit activity during stereotyped finger tasks and computer mouse work. Journal of Electromyography and Kinesiology. 2001 Jun 1;11(3):197206.

6. Sjøgaard G, Jensen BR. Low-Level Static Exertions in the Workplace. In: Fundamentals and Assessment Tools for Occupational Ergonomics. Edited by William S. Marras and Waldemar Karwowski. CRC Press 2006, 14-1-14-13.

7. Agarabi M, Bonato P, De Luca CJ. A sEMG-based method for assessing the design of computer mice. InThe 26th Annual International Conference of the IEEE Engineering in Medicine and Biology Society 2004 Sep 1 (Vol. 1, pp. 2450-2453). IEEE.

8. Lee DL, Fleisher J, McLoone HE, Kotani K, Dennerlein JT. Alternative computer mouse design and testing to reduce finger extensor muscle activity during mouse use. Human Factors. 2007 Aug;49(4):573-84.

9. Lee DL, McLoone H, Dennerlein JT. Observed finger behaviour during computer mouse use. Applied Ergonomics. 2008 Jan 1;39(1):107-13.

10. Bleecker ML, Celio MA, Barnes SK. A medical-ergonomic program for symptomatic keyboard/mouse users. Journal of occupational and environmental medicine. 2011 May 1;53(5):562-8.

11. Lin MY, Young JG, Dennerlein JT. Evaluating the effect of four different pointing device designs on upper extremity posture and muscle activity during mousing tasks. Applied Ergonomics. 2015 Mar $1 ; 47: 259-64$. 
12. Jensen C, Borg V, Finsen L, Hansen K, Juul-Kristensen B, Christensen H. Job demands, muscle activity and musculoskeletal symptoms in relation to work with the computer mouse. Scandinavian journal of work, environment \& health. 1998 Oct 1:418-24.

13. Karlqvist L, Hagberg M, Selin K. Variation in upper limb posture and movement during word processing with and without mouse use. Ergonomics. 1994 Jul 1;37(7):1261-7.

14. ISO 9241-400:2007.: Ergonomics of human-system interaction - part 400: Principles and requirements for physical input devices (2007)

15. Hemati K, Mirjalili S, Ghasemi MS, Abdolahian Y, Siroos R, Sanati P, Aghilinejad M, Dehghan N. Functional parameters, wrist posture deviations and comfort: A comparison between a computer mouse and a touch pen as input devices. Work. 2020 Jan 1;65(4):701-6.

16. Lourenço ML, Pitarma RA, Coelho DA. Horizontal and vertical handheld pointing devices comparison for increasing human systems integration at the design stage. In Advances in Human Factors and System Interactions 2017 (pp. 15-24). Springer, Cham.

17. Lourenço LM. Desenvolvimento e análise ergonómica de dispositivos manuais apontadores para computador. [Development and Ergonomic Analysis of Computer Handheld Pointing Devices]. Doctoral Dissertation. Industrial Engineering and Management. School of Engineering. Universidade da Beira Interior, Covilhã, Portugal (2016).

18. Ullman J, Kangas N, Ullman P, Wartenberg F, Ericson M. A new approach to the mouse arm syndrome. International Journal of Occupational Safety and Ergonomics. 2003 Jan 1;9(4):463-77.

19. Burgess-Limerick R, Shemmell J, Scadden R, Plooy A. Wrist posture during computer pointing device use. Clinical Biomechanics. 1999 May 1;14(4):280-6.

20. Chaparro A, Rogers M, Fernandez J, Bohan M, Sang Dae C, Stumpfhauser L. Range of motion of the wrist: implications for designing computer input devices for the elderly. Disability and rehabilitation. 2000 Jan 1;22(13-14):633-7. 
21. Keir PJ, Bach JM, Rempel D. Effects of computer mouse design and task on carpal tunnel pressure. Ergonomics. 1999 Oct 1;42(10):1350-60.

22. Lintula M, Nevala-Puranen N, Louhevaara V. Effects of Ergorest ${ }^{\circledR}$ arm supports on muscle strain and wrist positions during the use of the mouse and keyboard in work with visual display units: A work site intervention. International journal of occupational safety and ergonomics. 2001 Jan 1;7(1):103-16.

23. Kelaher D, Nay T, Lawrence B, Lamar S, Sommerich CM. An investigation of the effects of touchpad location within a notebook computer. Applied Ergonomics. 2001 Feb 1;32(1):101-10.

24. Cook CJ, Kothiyal K. Influence of mouse position on muscular activity in the neck, shoulder and arm in computer users. Applied ergonomics. 1998 Dec 4;29(6):439-43.

25. Harvey R, Peper E. Surface electromyography and mouse use position. Ergonomics. 1997 Aug 1;40(8):781-9.

26. Finsen L, Søgaard K, Jensen C, Borg V, Christensen H. Muscle activity and cardiovascular response during computer-mouse work with and without memory demands. Ergonomics. 2001 Nov $1 ; 44(14): 1312-29$.

27. Jensen C, Finsen L, Hansen K, Christensen H. Upper trapezius muscle activity patterns during repetitive manual material handling and work with a computer mouse. Journal of electromyography and kinesiology. 1999 Oct 1;9(5):317-25.

28. Karlqvist LK, Hagberg M, Köster M, Wenemark M, Anell R. Musculoskeletal symptoms among computer assisted design (CAD) operators and evaluation of a self-assessment questionnaire. International Journal of Occupational and Environmental Health. 1996 Jul 1;2(3):185-94.

29. Chen HM, Lee CS, Cheng CH. The weight of computer mouse affects the wrist motion and forearm muscle activity during fast operation speed task. European journal of applied physiology. 2012 Jun $1 ; 112(6): 2205-12$. 
30. Wahlström J, Hagberg M, Johnson P, Svensson J, Rempel D. Influence of time pressure and verbal provocation on physiological and psychological reactions during work with a computer mouse. European journal of applied physiology. 2002 Jul 1;87(3):257-63.

31. Criswell E. Cram's introduction to surface electromyography. Jones \& Bartlett Publishers; 2010 Oct 22.

32. Houwink A, Oude Hengel KM, Odell D, Dennerlein JT. Providing training enhances the biomechanical improvements of an alternative computer mouse design. Human Factors. 2009 Feb;51(1):46-55.

33. Rempel DM. Personal communications regarding appropriate surface EMG equipment and selection of muscles for monitoring. Professor of Occupational Medicine, University of California, San Francisco CA (2013-2015)

34. Perotto AO. Anatomical guide for the electromyographer: the limbs and trunk. Charles C Thomas Publisher; 1994.

35. Odell DL, Johnson PW. Evaluation of a mouse designed to improve posture and comfort. In Proceedings of the 2007 Work with Computing Systems Conference-International Ergonomics Association 2007.

36 Odell D, Johnson P. Evaluation of flat, angled, and vertical computer mice and their effects on wrist posture, pointing performance, and preference. Work. 2015 Jan 1;52(2):245-53.

37. Pheasant S, Haslegrave CM. Bodyspace: Anthropometry, ergonomics and the design of work. CRC Press; 2005.

38. Higgins JS, Willems B, Johnson DR, Zingale CM. A human factors and electromyographic evaluation of proposed pointing devices for air traffic controllers. In Proceedings of the Human Factors and Ergonomics Society Annual Meeting 2012 Sep (Vol. 56, No. 1, pp. 36-40). Sage CA: Los Angeles, CA: SAGE Publications. 
39. Young JG, Trudeau MB, Odell D, Marinelli K, Dennerlein JT. Wrist and shoulder posture and muscle activity during touch-screen tablet use: effects of usage configuration, tablet type, and interacting hand. Work. 2013 Jan 1;45(1):59-71.

40. Eijckelhof BH, Huysmans MA, Garza JB, Blatter BM, Van Dieën JH, Dennerlein JT, Van Der Beek AJ. The effects of workplace stressors on muscle activity in the neck-shoulder and forearm muscles during computer work: a systematic review and meta-analysis. European Journal of Applied Physiology. 2013 Dec 1;113(12):2897-912.

41. Garza JL, Eijckelhof BH, Huysmans MA, Johnson PW, van Dieen JH, Catalano PJ, Katz JN, van der Beek AJ, Dennerlein JT. Prediction of trapezius muscle activity and shoulder, head, neck, and torso postures during computer use: results of a field study. BMC musculoskeletal disorders. 2014 Dec;15(1):292.

42. Kluth K, Keller E. Rollermouse vs. Standard Computer Mouse-Electromyographic and Subjective Assessment of the Usability in Applications with Graphical user interfaces. Advances in Physical Ergonomics and Human Factors: Part I. 2014 Jul 19;14:235.

43. Hagberg M. The amplitude distribution of surface EMG in static and intermittent static muscular performance. European journal of applied physiology and occupational physiology. 1979 Dec $1 ; 40(4): 265-72$.

44. Jonsson B. The static load component in muscle work. European journal of applied physiology and occupational physiology. 1988 May 1;57(3):305-10.

45. Coelho DA, Lourenço ML. A tentative efficiency index for pointing device use in computer aided design: A pilot study. Work (Reading, Mass.). 2018;61(1):157-70.

46. Hengel KM, Houwink A, Odell D, van Dieën JH, Dennerlein JT. Smaller external notebook mice have different effects on posture and muscle activity. Clinical Biomechanics. 2008 Jul 1;23(6):727-34. 
47. Clarisse G, Cail F, Pascal W. Comparing learning during the familiarization phase with a slanted mouse and a vertical mouse when performing a repeated pointing-clicking task. International Journal of Occupational Safety and Ergonomics. 2020 Apr 10(just-accepted):1-22. 
Table 1. Muscle activation

\begin{tabular}{lllll} 
& \multicolumn{4}{c}{ Muscle } \\
\cline { 2 - 5 } Behavioral & \multicolumn{1}{c}{ ECR } & \multicolumn{1}{c}{ ECU } & \multicolumn{1}{c}{ ED } & \multicolumn{1}{c}{ APL } \\
\cline { 2 - 5 } Test & $\begin{array}{l}\text { Wrist } \\
\text { extension } \\
\text { and radial } \\
\text { deviation }\end{array}$ & $\begin{array}{l}\text { Ulnar } \\
\text { deviation } \\
\text { of the } \\
\text { wrist }\end{array}$ & $\begin{array}{l}\text { Finger } \\
\text { extension }\end{array}$ & $\begin{array}{l}\text { Abduction } \\
\text { of the } \\
\text { thumb } \\
\text { (thumb }\end{array}$
\end{tabular}

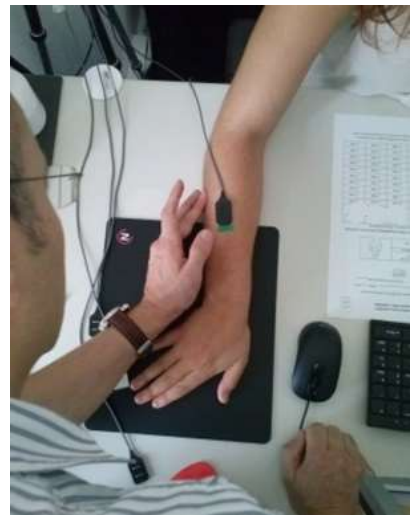

Fig. 1. Electrode placement procedures (behavioral test with palpation of the active muscle). 


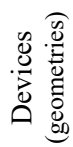
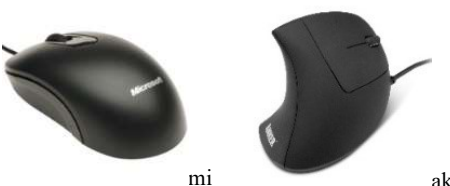

ak

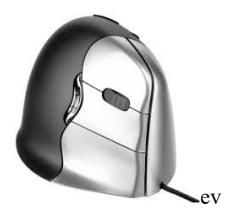

Resolution

(dots per

inch)

Overall dimensions

$106 \times 56 \times 36 \mathrm{~mm}$

wire

Mass, with wire

supported in the

horizontal work

plane

Slant angle with

reference to the

horizontal plane
$78 \mathrm{~g}$

1000

1000

$120 \times 63 \times 75 \mathrm{~mm}$

$145 \mathrm{~g}$

$119 \mathrm{~g}$

$57 \mathrm{~g}$

$0^{\circ}$
$137 \mathrm{~g}$

1300

$111 \times 89 \times 77 \mathrm{~mm}$

$170 \mathrm{~g}$

$90^{\circ}$

Fig. 2. Handheld pointing devices evaluated. 



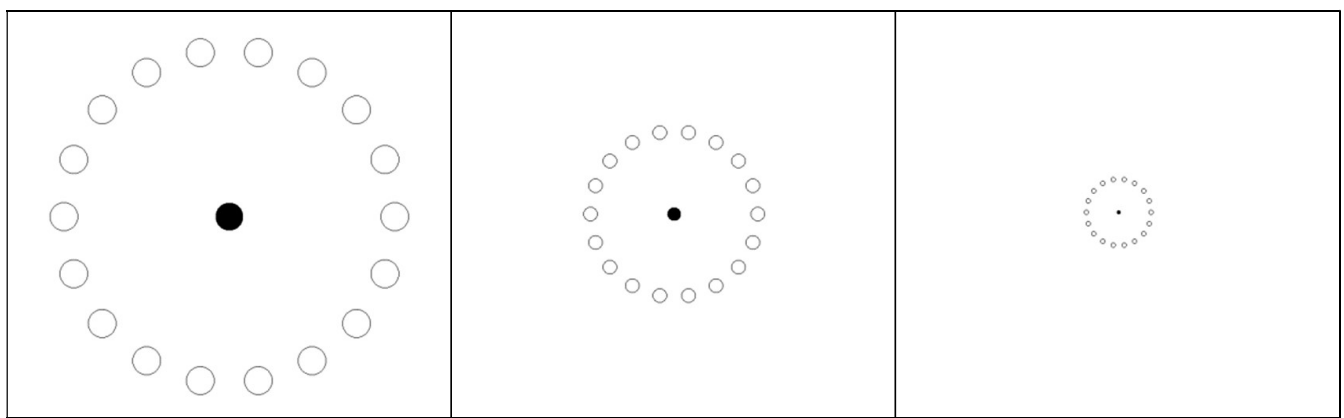

Pointing Large

Pointing Medium

18 randomized locations Greatest test diameter $71 \mathrm{~mm}$ Circle diameter $6 \mathrm{~mm}$ $\mathrm{mm}$

Circle diameter $12 \mathrm{~mm}$

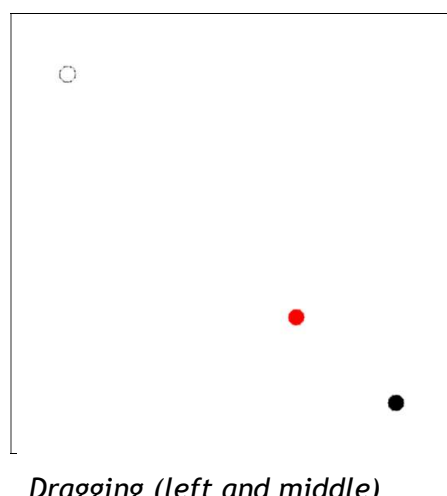

Dragging (left and middle)

8 randomized directions Test diameter $200 \mathrm{~mm}$ Circle diameter $7 \mathrm{~mm}$
Pointing Small

18 randomized locations

Greatest test diameter $28 \mathrm{~mm}$ Circle diameter $2 \mathrm{~mm}$

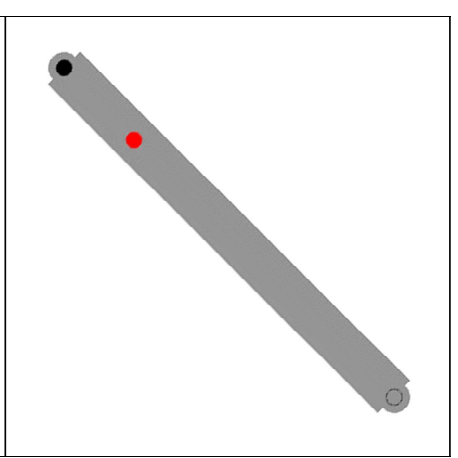

Steering

8 randomized directions Distance between targets 200 $\mathrm{mm}$

Circle diameter $7 \mathrm{~mm}$

Figure 3 - Test tasks (pointing, dragging and steering). 
Table 2 - Characterization of the sample of participants separated by gender

\begin{tabular}{ccccccccc}
\hline \multicolumn{3}{c}{ Participants } & \multicolumn{2}{c}{ Age (years) } & Hand length $(\mathrm{mm})$ & \multicolumn{2}{c}{ Hand width (mm) } \\
\hline $\begin{array}{c}\text { Number of } \\
\text { participants }\end{array}$ & Sex & $\begin{array}{c}\text { CAD } \\
\text { practitioner }\end{array}$ & Mean (SD) & Range & Mean (SD) & Range & Mean (SD) & Range \\
\hline 10 & Feminine & 10 & $23.1(2.7)$ & $20-29$ & $173.2(7.1)$ & $160-183$ & $77.7(4.6)$ & $72-85$ \\
10 & Masculine & 10 & $25.4(2.6)$ & $22-30$ & $192.2(9.9)$ & $170-208$ & $92.6(2.8)$ & $86-96$ \\
\hline
\end{tabular}

Table 3 - Characterization of the overall sample of participants and in what concerns hand size groups

\begin{tabular}{|c|c|c|c|c|c|c|c|c|c|}
\hline \multicolumn{2}{|c|}{ Participants } & \multicolumn{2}{|c|}{ Age (years) } & \multicolumn{2}{|c|}{ Hand length (mm) } & \multicolumn{2}{|c|}{ Hand width (mm) } & \multicolumn{2}{|c|}{$\begin{array}{l}\text { Auxuliary parameter } \\
\text { Length + Width }\end{array}$} \\
\hline $\begin{array}{l}\text { Number of } \\
\text { participants }\end{array}$ & $\begin{array}{l}\text { CAD } \\
\text { practiti } \\
\text { oner }\end{array}$ & $\begin{array}{c}\text { Mean } \\
\text { (SD) }\end{array}$ & Range & $\begin{array}{l}\text { Mean } \\
\text { (SD) }\end{array}$ & Range & $\begin{array}{c}\text { Mean } \\
\text { (SD) }\end{array}$ & Range & $\begin{array}{l}\text { Mean } \\
(\mathrm{SD})\end{array}$ & Range \\
\hline 20 & 20 & $\begin{array}{l}24.3 \\
(2.9)\end{array}$ & $20-30$ & $\begin{array}{l}182.7 \\
(12.8)\end{array}$ & $160-208$ & $\begin{array}{l}85.2 \\
(8.4)\end{array}$ & $72-96$ & $\begin{array}{l}267.9 \\
(19.8)\end{array}$ & $232-302$ \\
\hline 11 & \multicolumn{8}{|c|}{ participants whose hand size is less than the sample mean hand size } & $232-265$ \\
\hline 9 & \multicolumn{8}{|c|}{ participants whose hand size is greater than the sample mean hand size } & $275-302$ \\
\hline
\end{tabular}

\begin{tabular}{ccccccc}
\hline Activity & $\begin{array}{c}\text { Pointing at large } \\
\text { targets }\end{array}$ & $\begin{array}{c}\text { Pointing at } \\
\text { medium targets }\end{array}$ & $\begin{array}{c}\text { Pointing at small } \\
\text { targets }\end{array}$ & $\begin{array}{c}\text { Dragging with } \\
\text { left button }\end{array}$ & $\begin{array}{c}\text { Dragging with } \\
\text { middle button }\end{array}$ & Steering \\
\hline Time Fraction & $10.1 \%$ & $21.8 \%$ & $18.1 \%$ & $23.1 \%$ & $11.2 \%$ & $15.7 \%$
\end{tabular}

Table 4 - Characterization of relative time fraction for each of the computer mice use activities monitored. 
Time Weighted APDF90 [\% of MVC] by hand size and device angle

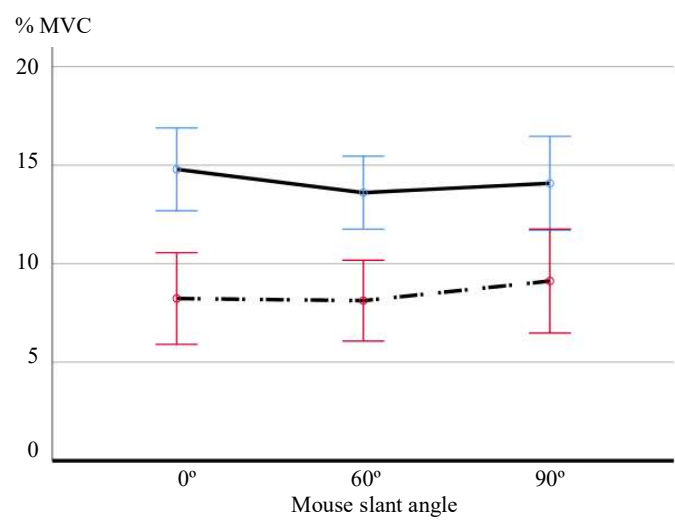

Time Weighted APDF50 [\% of MVC] by hand size and device angle

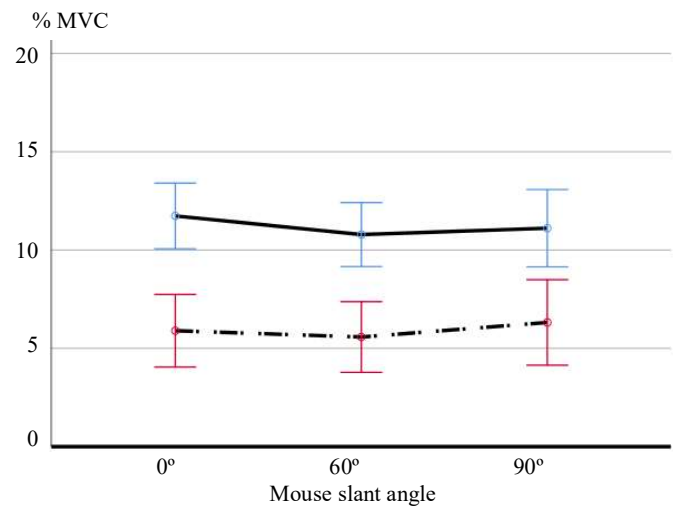

Time Weighted APDF 10 [\% of MVC] by hand size and device angle

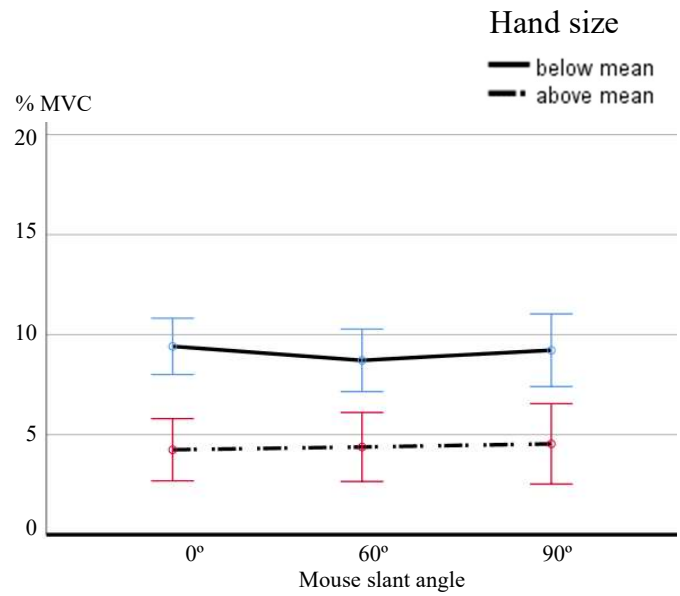

Time Weighted Dynamic Index [dimensionless] by hand size and device angle

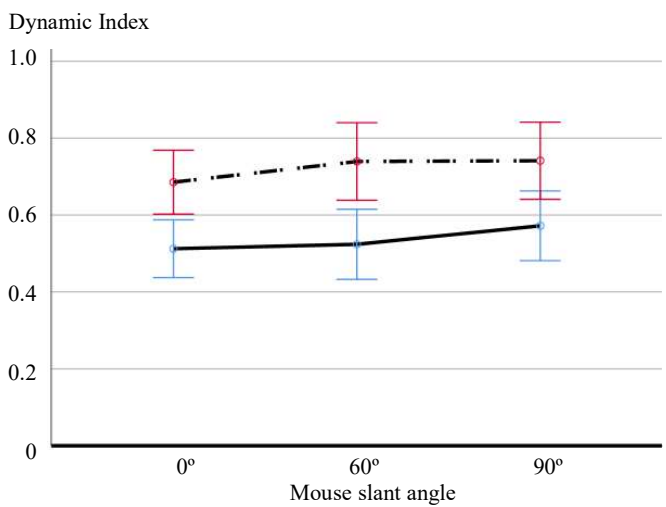

Fig. 4 - APL muscle activation analysis (error bars: +/- 1 Standard Error) for APDF90, 50 and 10 as well as Dynamic Index. 
Time Weighted APDF90 [\% of MVC] by hand size and device angle

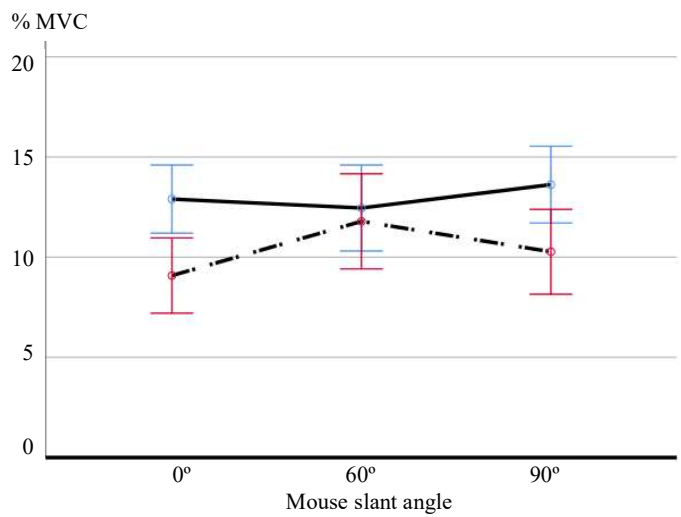

Time Weighted APDF50 [\% of MVC] by hand size and device angle

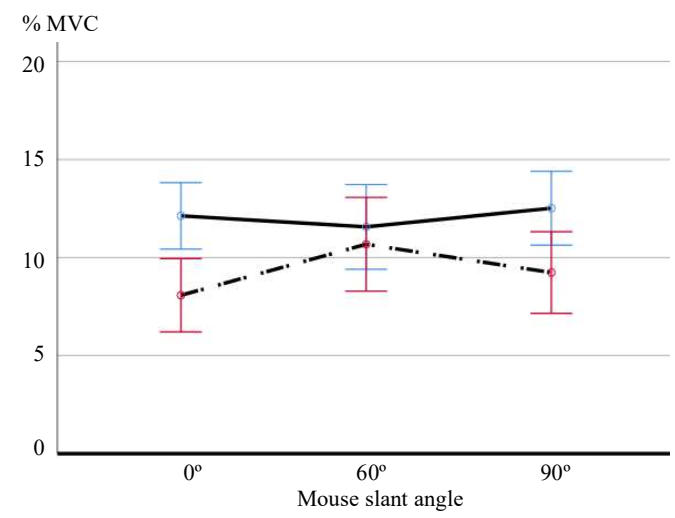

Time Weighted APDF10 [\% of MVC] by hand size and device angle

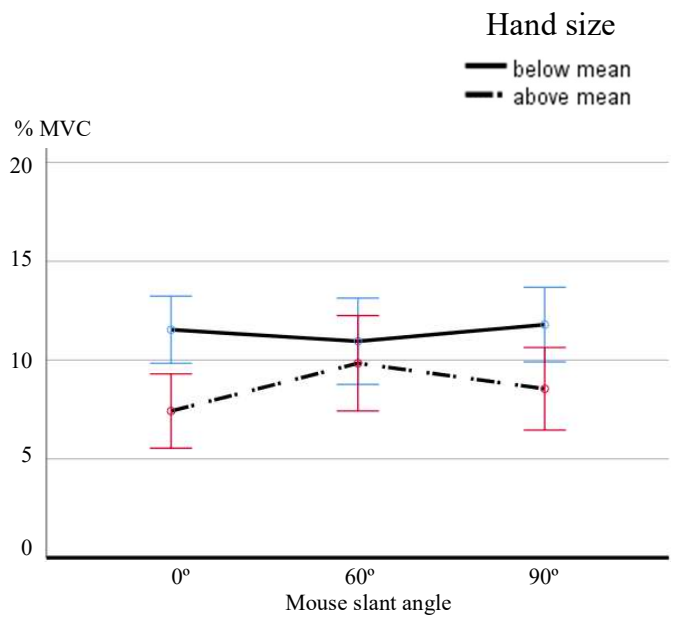

Time Weighted Dynamic Index [dimensionless] by hand size and device angle

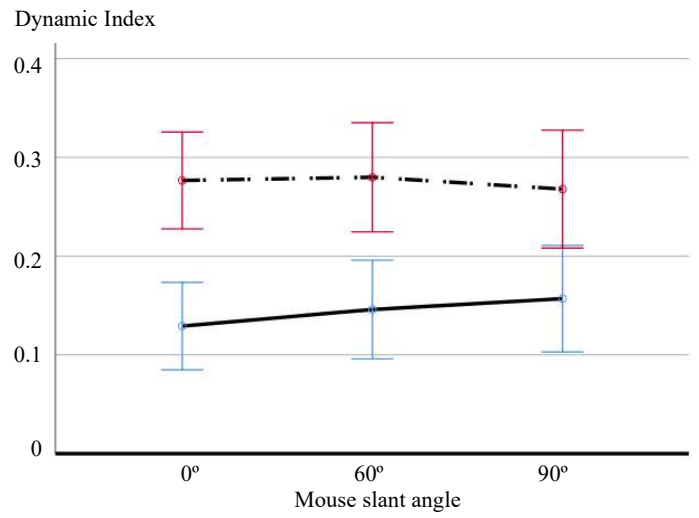

Fig. 5 - ECR muscle activation analysis (error bars: +/- 1 Standard Error) for APDF90, 50 and 10 as well as Dynamic Index. 
Time Weighted APDF90 [\% of MVC] by hand size and device angle

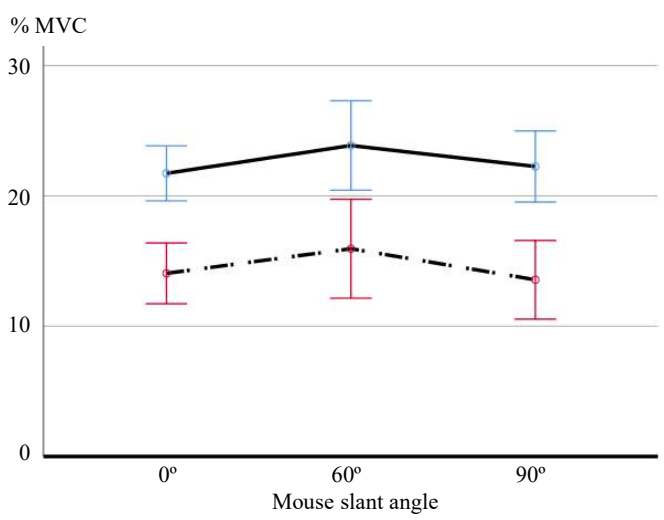

Time Weighted APDF50 [\% of MVC] by hand size and device angle

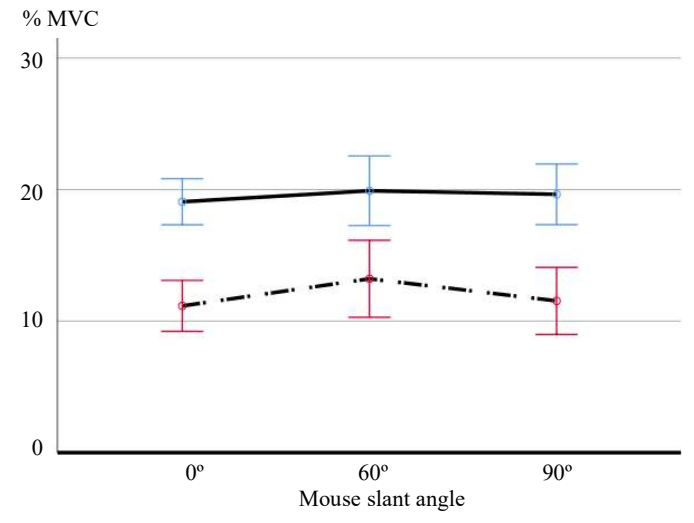

Time Weighted APDF10 [\% of MVC] by hand size and device angle

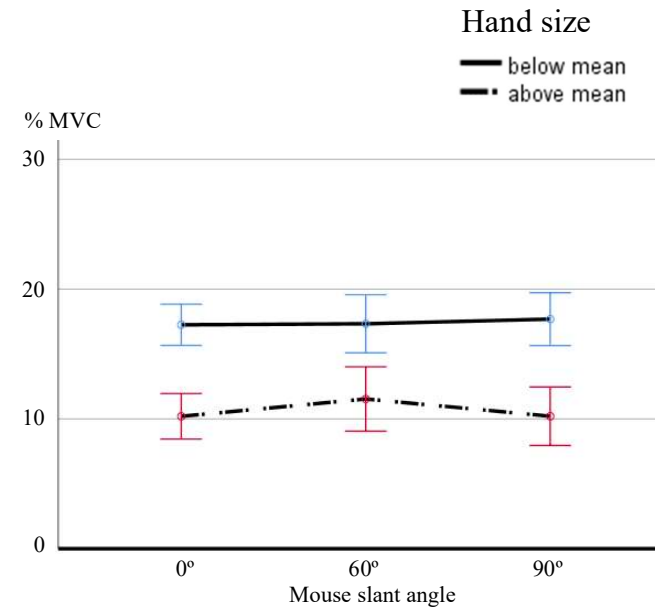

Time Weighted Dynamic Index [dimensionless] by hand size and device angle

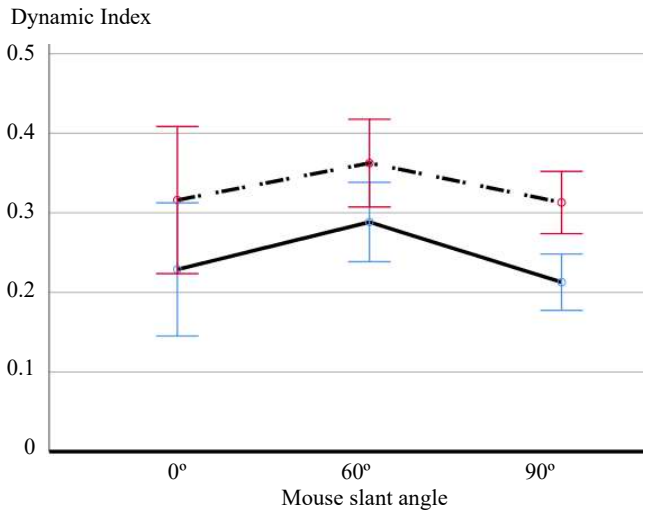

Fig. 6 - ECU muscle activation analysis (error bars: +/- 1 Standard Error) for APDF90, 50 and 10 as well as Dynamic Index. 
Time Weighted APDF90 [\% of MVC] by hand size and device angle

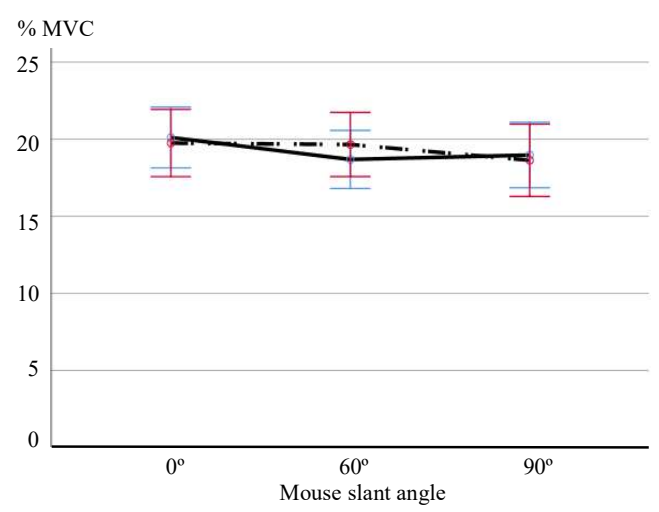

Time Weighted APDF50 [\% of MVC] by hand size and device angle

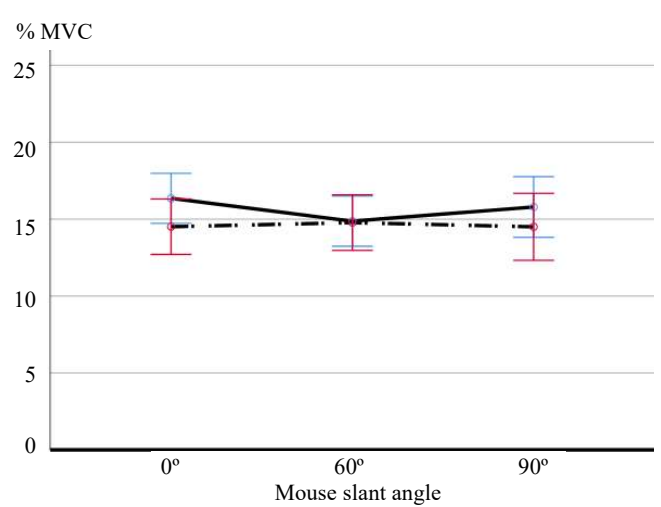

Time Weighted APDF10 [\% of MVC] by hand size and device angle



Time Weighted Dynamic Index [dimensionless] by hand size and device

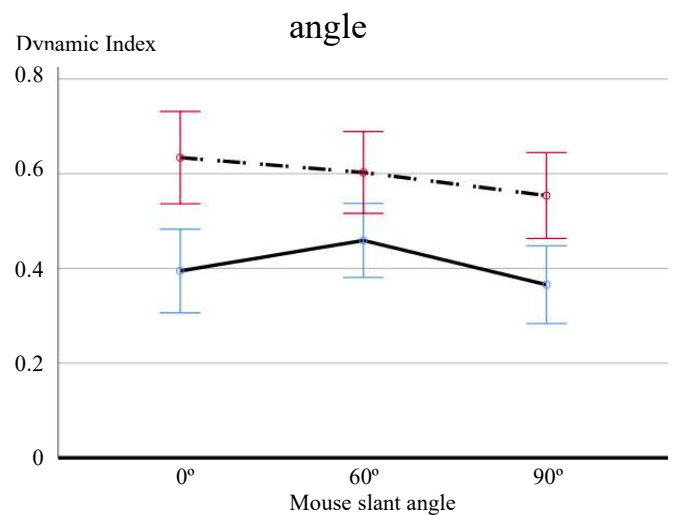

Fig. 7 - ED muscle activation analysis (error bars: +/- 1 Standard Error) for APDF90, 50 and 10 as well as Dynamic Index. 